\title{
Dispersive liquid-liquid microextraction of silver nanoparticles in water using ionic liquid 1-octyl-3-methylimidazolium hexafluorophosphate
}

\author{
Sha Chen ${ }^{1}$, Yuanjing Sun ${ }^{1,2}$, Jingbo Chao, ${ }^{2, *}$, Liping Cheng ${ }^{1}$, Yun Chen ${ }^{1}$, Jingfu Liu ${ }^{3}$ \\ 1. Key Laboratory of Beijing on Regional Air Pollution Control, Beijing University of Technology, Beijing 100124, China. E-mail: shachen68@163.com \\ 2. Chemical Metrology and Analytical Science Division, National Institute of Metrology, Beijing 100031, China \\ 3. State Key Laboratory of Environmental Chemistry and Ecotoxicology, Research Center for Eco-Environmental Sciences, Chinese Academy of \\ Sciences, Beijing 100085, China
}

\section{A R T I C L E I N F O}

Article history:

Received 4 March 2015

Revised 8 April 2015

Accepted 9 April 2015

Available online 4 July 2015

Keywords:

Silver nanoparticle

1-Octyl-3-methylimidazolium

hexafluorophosphate

Ionic liquid

Dispersive liquid-liquid

microextraction

\begin{abstract}
A B S T R A C T
Using the ionic liquid (IL) 1-octyl-3-methylimidazolium hexafluorophosphate as the extractant and methanol as the dispersion solvent, a dispersive liquid-liquid microextraction method was developed to extract silver nanoparticles (AgNPs) from environmental water samples. Parameters that influenced the extraction efficiency such as IL concentration, $\mathrm{pH}$ and extraction time were optimized. Under the optimized conditions, the highest extraction efficiency for AgNPs was above $90 \%$ with an enrichment factor of $>90$. The extracted AgNPs in the IL phase were identified by transmission electron microscopy and ultraviolet-visible spectroscopy, and quantified by inductively coupled plasma mass spectrometry after microwave digestion, with a detection limit of $0.01 \mu \mathrm{g} / \mathrm{L}$. The spiked recovery of AgNPs was $84.4 \%$ with a relative standard deviation (RSD) of $3.8 \%(n=6)$ at a spiked level of $5 \mu \mathrm{g} / \mathrm{L}$, and $89.7 \%$ with a RSD of $2.2 \%(n=6)$ at a spiked level of $300 \mu \mathrm{g} / \mathrm{L}$, respectively. Commonly existed environmental ions had a very limited influence on the extraction efficiency. The developed method was successfully applied to the analysis of AgNPs in river water, lake water, and the influent and effluent of a wastewater treatment plant, with recoveries in the range of $71.0 \%-90.9 \%$ at spiking levels of $0.11-4.7 \mu \mathrm{g} / \mathrm{L}$. (c) 2015 The Research Center for Eco-Environmental Sciences, Chinese Academy of Sciences.
\end{abstract}

Published by Elsevier B.V.

\section{Introduction}

Silver nanoparticles (AgNPs) have been applied in various products, such as plastics, household textiles, medicine, and cosmetics, due to their excellent antimicrobial properties (Benn and Westerhoff, 2008; Blaser et al., 2008; Emam et al., 2013; Meyer et al., 2011; Quadros and Marr, 2011; Sondi and Salopek-Sondi, 2004; Shahverdi et al., 2007; Sallum et al., 2014; Tolaymat et al., 2010). As a result, AgNPs can be released into the environment, and result in potential risk to human beings and other biological organisms (Li et al., 2012; Khan et al., 2011; Losert et al., 2014; Sharma et al., 2014; Tian et al., 2013; Yu et al., 2012). It was reported that orally delivered AgNPs induced deleterious effects on the liver and heart for mammals (Elle et al., 2013). Additionally, AgNPs could accumulate and transport along the food chain (Zhao and Wang, 2010). However, the mechanism of AgNP toxicity is not clear, although it was reported that the morphological

\footnotetext{
* Corresponding author. E-mail: chaojb@nim.ac.cn (Jingbo Chao).
} 
characteristics such as surface charge, particle size and shape were related to their toxicity (Badawy et al., 2011; Burkowska-But et al., 2014; Carlson et al., 2008; Pal et al., 2007). This lack of knowledge could be ascribed to the complexity of nanoparticles themselves, as well as the lack of methods that are capable of monitoring the trace AgNPs from complex environmental and biological samples without disturbing their characteristics (Farré et al., 2011).

To date, several methods have been developed for the separation and determination of AgNPs such as field flow fractionation, anodic particle coulometry, and hydrodynamic chromatography, but these methods have limitations to varying extents, for example, poor resolution, time consuming and overly elaborate procedures (Liu et al., 2012; Bednar et al., 2013; Stuart et al., 2012; Tiede et al., 2009). Liu et al. first established the Triton X-114-based cloud point extraction method for analysis of trace AgNPs in river water, which was then used to detect AgNPs in samples from wastewater treatment plants (WWTP) (Liu et al., 2009a; Chao et al., 2011; Li et al., 2013) and in lixiviates obtained from sticking plasters and cleaning cloths (López-García et al., 2014).

Because of their unique properties such as negligible vapor pressure, good thermal stability and miscibility with water, ionic liquids (ILs) have been widely used in separation technology (Han and Row, 2010; Liu et al., 2005, 2009b; Tan et al., 2012). They have been applied for extraction of some nanoparticles. It was suggested that the extraction was achieved through anion exchange, and it was proved that the formation of a hydrophobic ion-pair between the stabilizer and ILs promoted the extraction (Zhao et al., 2006; Lee et al., 2010). Gold nanoparticles (López-Lorente et al., 2012), copper nanoparticles (Huang et al., 2006), $\mathrm{Fe}_{3} \mathrm{O}_{4}$ (Zhang et al., 2012), $\mathrm{ZnO}$ and ZnS nanoparticles (Huang et al., 2009) were successfully recycled from environmental water samples (López-Lorente et al., 2012; Huang et al., 2006; Zhang et al., 2012) and phosphor wastes (Huang et al., 2009) with ILs. Unlike these nanoparticles, AgNPs often coexisted with $\mathrm{Ag}^{+}$, thus making it more difficult to separate and concentrate AgNPs from real samples than other nanoparticles (Yu et al., 2012).

Dispersive liquid-liquid microextraction (DLLME), first introduced by Rezaee et al. (2006), has been used for extraction of analytes from aqueous samples due to its advantages including high enrichment factor, simplicity of operation, and low cost (Zhang et al., 2013; Ojeda and Rojas, 2011). In addition, IL-based dispersive liquid-liquid microextraction (IL-DLLME) was also used in the extraction of not only organics like phenolic compounds (Jiang et al., 2011), phthalate (Chen et al., 2011) and fluoroquinolones (Vázquez et al., 2012), but also inorganic elements and species such as $\mathrm{Au}(\mathrm{III}) / \mathrm{Ag}(\mathrm{I})$ (Ashkenani and Taher, 2012), Tl(I) (Anthemidis and Ioannou, 2012), Cr(III) and Cr(VI) (López-García et al., 2012) from water samples.

The objective of this article is to develop a novel, convenient and efficient DLLME method to pre-concentrate trace AgNPs from water samples using 1-octyl-3-methylimidazolium hexafluorophosphate ([OMIM] $\left[\mathrm{PF}_{6}\right]$ ) as the extraction solvent. The extracted AgNPs in the IL phase were characterized by ultraviolet-visible (UV-Vis) absorbance spectra and transmission electron microscopy (TEM), and quantified by inductively coupled plasma mass spectrometry (ICP-MS) after microwave digestion.

\section{Materials and methods}

\subsection{Chemicals and materials}

A stock suspension of PVP (polyvinylpyrrolidone) capped AgNPs (AGS-WP001) was purchased from HZ NANO (HuZheng Nanotechnology Co., Ltd, Shanghai, China). [OMIM]PF 6 was purchased from Lanzhou Institute of Chemical Physics (Lanzhou, China). Methanol and nitric acid (65\%) were from Merck (Darmstadt, Germany). Certified reference material GBW $08610(1000 \mu \mathrm{g} / \mathrm{mL}$, National Institute of Metrology, Beijing, China) was used as the silver stock solution. Other chemicals were analytical-reagent grade or above and purchased from Sinopharm Chemical Reagent Beijing (Beijing, China). The water used throughout the study was from a Millipore Milli-Q deionized-water system (Billerica, MA, USA). The centrifugal filter units used for separating $\mathrm{Ag}^{+}$from AgNPs in the stock solution were cellulose membranes with 1-2 $\mathrm{nm}$ pore size from Amicon centrifugal ultrafilter units (Ultra-15, 3K, Millipore, Billerica, MA, USA).

\subsection{Determination of AgNPs in stock dispersion}

The free $\mathrm{Ag}^{+}$concentration in the AgNP stock dispersion was determined by ICP-MS (Agilent 7500ce, Palo Alto, USA) after ultrafiltration with Sigma 3-18 K (Sigma, Osterode am Harz, Germany) at $9600 \mathrm{r} / \mathrm{min}$ at $4^{\circ} \mathrm{C}$ for $25 \mathrm{~min}$, while the total silver in the dispersion was determined by ICP-MS after microwave-assisted digestion (CEM Mars 5, Xpress, Matthews, NC, USA) as described in our previous study (Liu et al., 2009a). The content of AgNPs in the stock dispersion was obtained by subtracting the content of free $\mathrm{Ag}^{+}$from total silver. The AgNP stock dispersions were kept in the dark and used for one week, and the working dispersions were prepared and quantified by ICP-MS daily.

\subsection{Extraction procedure}

$0.1 \mathrm{~g}$ [OMIM] $\left[\mathrm{PF}_{6}\right]$ was added into a $15 \mathrm{~mL}$ long tapered Corning tube followed by $1 \mathrm{~mL}$ methanol, and the tube was hand shaken for a few seconds to mix with the IL. $9 \mathrm{~mL}$ of AgNP sample solution was added subsequently to obtain a milky turbid liquid. The mixture was mixed and incubated in a thermostatic water bath oscillator at $30^{\circ} \mathrm{C}$ for $30 \mathrm{~min}$ with a shaking velocity of $200 \mathrm{r} / \mathrm{min}$. Then the tube was centrifuged at $4500 \mathrm{r} / \mathrm{min}$ for $5 \mathrm{~min}$ to facilitate the phase separation. Finally, the IL phase with concentrated AgNPs was collected for quantitative detection or characterization.

\subsection{Characterization of AgNPs}

The absorbance spectra of AgNPs before and after extraction were detected by a UV-Vis spectrophotometer (8453, Agilent Technology, Santa Clara, CA, USA), and TEM images were obtained for samples on carbon-coated grid sample holders with an H-7500 transmission electron microscope (Hitachi, Tokyo, Japan) at $80 \mathrm{kV}$. AgNPs enriched in the IL phase were dispersed and diluted by methanol or a mixture of water and methanol (1:1) for UV-Vis and TEM, respectively. 


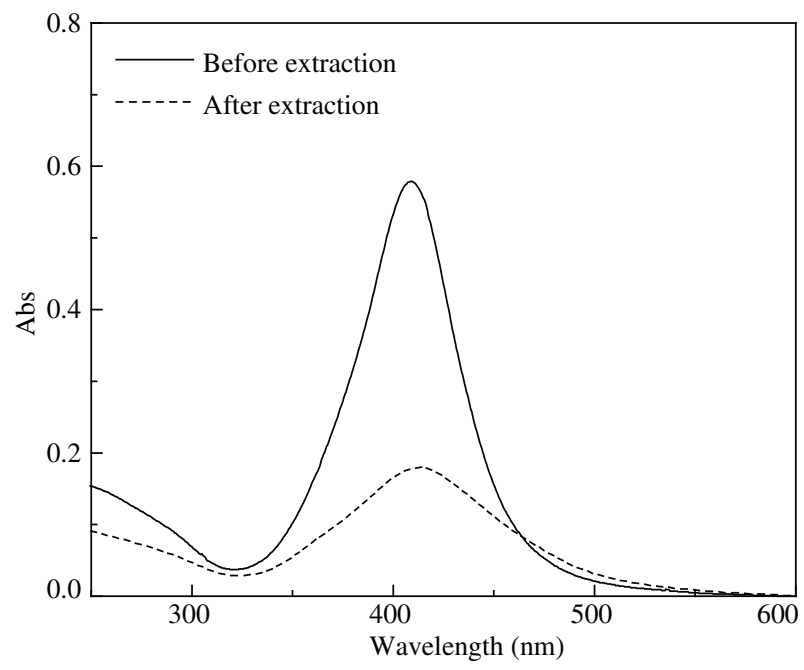

Fig. 1 - Ultraviolet-visible spectroscopy (UV-Vis) spectra of silver nanoparticles (AgNP) before and after extraction.

\subsection{Determination of AgNPs with ICP-MS}

In order to determine the concentration of the extracted AgNPs, the IL phase was digested with a microwave-assisted digestion procedure modified from the previous study (Liu et al., 2009a). Briefly, $4 \mathrm{~mL}$ of concentrated $\mathrm{HNO}_{3}$ and $1 \mathrm{~mL}$ of $30 \% \mathrm{H}_{2} \mathrm{O}_{2}$ were added into the IL phase and then the mixture was irradiated at $120^{\circ} \mathrm{C}(800 \mathrm{~W})$ for $10 \mathrm{~min}$, followed by $180^{\circ} \mathrm{C}$ $(1600 \mathrm{~W})$ for $30 \mathrm{~min}$ to guarantee complete digestion. After digestion, the sample was diluted with water to $50 \mathrm{~mL}$ and stored at room temperature until analysis. The Ag working standard solution was prepared by diluting a certified reference material $(1000 \mu \mathrm{g} / \mathrm{mL} \mathrm{Ag}$, GBW 08610, National Institute of Metrology, Beijing, China) with $5 \%(\mathrm{~V} / \mathrm{V}) \mathrm{HNO}_{3}$. ${ }^{107} \mathrm{Ag}$ was chosen as the determination isotope and ${ }^{115} \mathrm{In}$ was used as an internal standard.

\subsection{Water sample preparation}

Influent and effluent water samples were collected from a WWTP located in Xian County (Hebei, China). River water and lake water samples were collected from the Jingmi River,
Yongding River, Olympic Green River, and Fuhai lake of the Summer Palace (Beijing, China). All samples were stored at $4^{\circ} \mathrm{C}$ for analysis after $\mathrm{pH}$ determination and filtered through a $0.22 \mu \mathrm{m}$ membrane syringe filter.

\section{Results and discussion}

\subsection{Confirmation of AgNPs after extraction}

The UV-Vis and TEM results for AgNPs before and after extraction are shown in Figs. 1 and 2, respectively. As shown in Fig. 1, the UV-Vis spectra of AgNPs in water and the IL phase exhibited a maximum absorbance of $411 \mathrm{~nm}$, which demonstrated the presence of AgNPs (Liu et al., 2009a). Fig. 2b shows that the sizes and shapes of AgNPs in the IL phase agreed well with those in the original sample solution, with particle diameters around $20 \mathrm{~nm}$ as shown in Fig. 2a. The UV-Vis and TEM results revealed that the IL-DLLME method could preserve the sizes and shapes of AgNPs during the extraction.

\subsection{Optimization of the extraction parameters}

As mentioned above, the AgNPs could preserve their characteristics during the IL-DLLME procedure. Using [OMIM] $\left[\mathrm{PF}_{6}\right]$ as the extractant and methanol as the dispersion agent, a series of parameters that commonly influence the extraction efficiency were optimized. Considering that insufficient IL results in inefficient extraction while excessive amount of IL may increase the average particle diameters of the transferred metal nanoparticles, due to the formation of hydrophobic ion-pairs on the nanoparticle surface (Lee et al., 2010), the IL concentration was optimized in the range of $0.5 \%-1.5 \%(\mathrm{~W} / \mathrm{V})$, and results are shown in Fig. 3a. It could be seen that the extraction efficiency increased with IL concentration up to $1 \%$ (W/V), whereas with further increase of IL concentration, the extraction efficiency declined slightly, which might be attributed to incomplete dispersion of ILs in methanol, and resulted in insufficient extraction. Therefore, $1 \%(\mathrm{~W} / \mathrm{V})$ [OMIM] $\left[\mathrm{PF}_{6}\right]$ was adopted in the subsequent studies.

Temperature and extraction time are two key factors impacting the extraction efficiency. Lower temperature and shorter incubation time resulted in incomplete dispersion of the

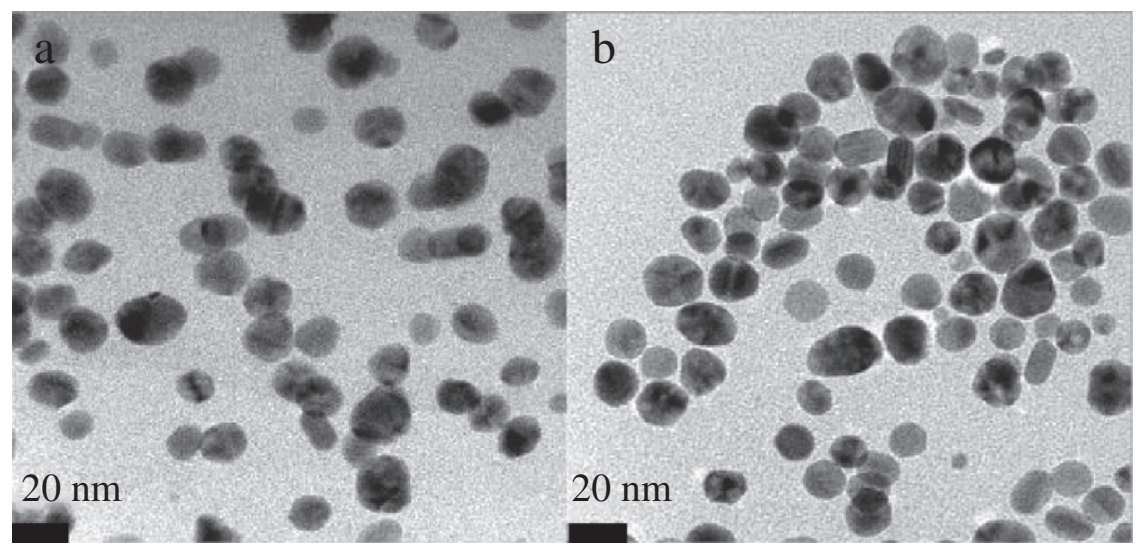

Fig. 2 - Transmission electron microscopy (TEM) images of AgNPs before (a) and after (b) extraction. 
AgNPs in the mixture. However, excessively incubation time might give rise to the aggregation of $[\mathrm{OMIM}]\left[\mathrm{PF}_{6}\right]$, while higher temperature could enhance the dissolution of $\left[\mathrm{OMIM}^{-}\left[\mathrm{PF}_{6}\right]\right.$ in solutions. As shown in Fig. $3 b$ and $c$, the highest extraction recoveries were obtained at the temperature of $30^{\circ} \mathrm{C}$ and incubation time of $30 \mathrm{~min}$, which were adopted in the following studies.

In order to completely and rapidly separate the IL phase and aqueous phase, the centrifugation rate and time were optimized. It was demonstrated that by centrifugation at $4500 \mathrm{r} / \mathrm{min}$ for $5 \mathrm{~min}$, the aqueous phase became clear and transparent, which indicated that the two phases were completely separated. After all parameters were optimized, the results showed that the extraction efficiency of AgNPs could be up to $91.4 \% \pm 0.6 \%$.

The effect of $\mathrm{pH}$ on the extraction efficiency of AgNPs was determined by quantification of the Ag content in the IL phase by ICP-MS. Results shown in Fig. 3d indicated that the extraction efficiency of AgNPs decreased with the increase of $\mathrm{pH}$ up to 8.1, and then increased with the further increase of $\mathrm{pH}$. The enhanced extraction efficiency of AgNPs after $\mathrm{pH} 10.3$ could be attributed to the co-extraction of the $\mathrm{Ag}_{2} \mathrm{O}$ formed by the reaction between $\mathrm{Ag}^{+}$and $\mathrm{OH}^{-}$(Liu et al., 2009a). To verify this speculation, the extraction efficiency of $\mathrm{Ag}^{+}$was tested at different $\mathrm{pH}$ values. Results showed that $88.2 \% \pm 3.8 \% \mathrm{Ag}^{+}$ could be extracted into the IL phase at pH 11 , but only $0.51 \% \pm$ $0.06 \%$ at $\mathrm{pH}$ 6.2, while at $\mathrm{pH} 3$, the extraction efficiency of $\mathrm{Ag}^{+}$ was $18.5 \% \pm 1.9 \%$. Given that low $\mathrm{pH}$ may enhance the release of $\mathrm{Ag}^{+}$from AgNPs with weak capping agents, $\mathrm{pH} 6.2$ was chosen in the following experiments.

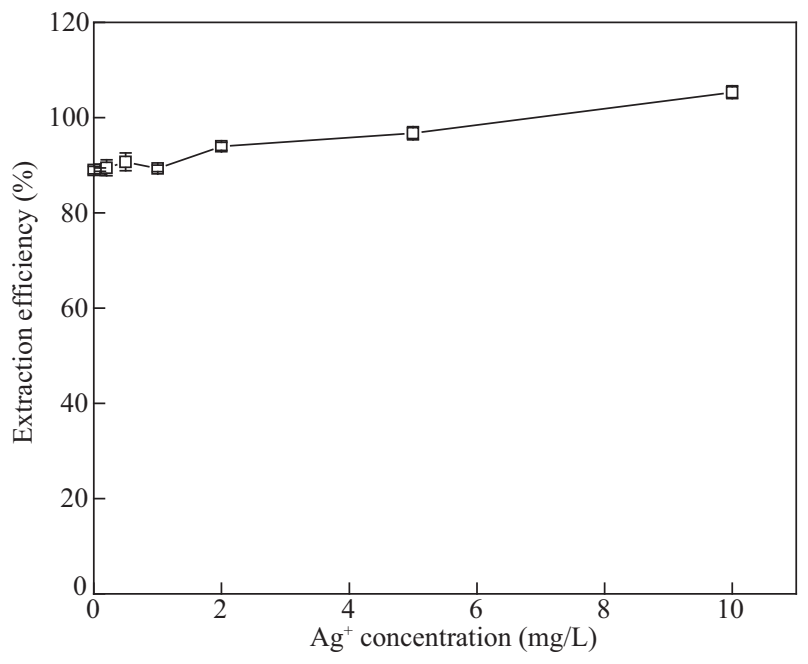

Fig. 4 - Effects of $\mathrm{Ag}^{+}$on the extraction efficiency of AgNPs. A $10 \mathrm{~mL}$ mixture of $0.931 \mathrm{mg} / \mathrm{L}$ AgNPs and $1 \%(\mathrm{~W} / \mathrm{V})$ [OMIM] $\left[\mathrm{PF}_{6}\right]$ with different $\mathrm{Ag}^{+}$content was adopted for studying the effect of $\mathrm{Ag}^{+}$, and the mixture was incubated at $30^{\circ} \mathrm{C}$ for $30 \mathrm{~min}$.

\subsection{Effects of interferences}

The coexisting $\mathrm{Ag}^{+}$might be adsorbed on the surface of AgNPs and coextracted into the extracted phase, which would result in positive errors (Liu et al., 2009a). Therefore, complexing
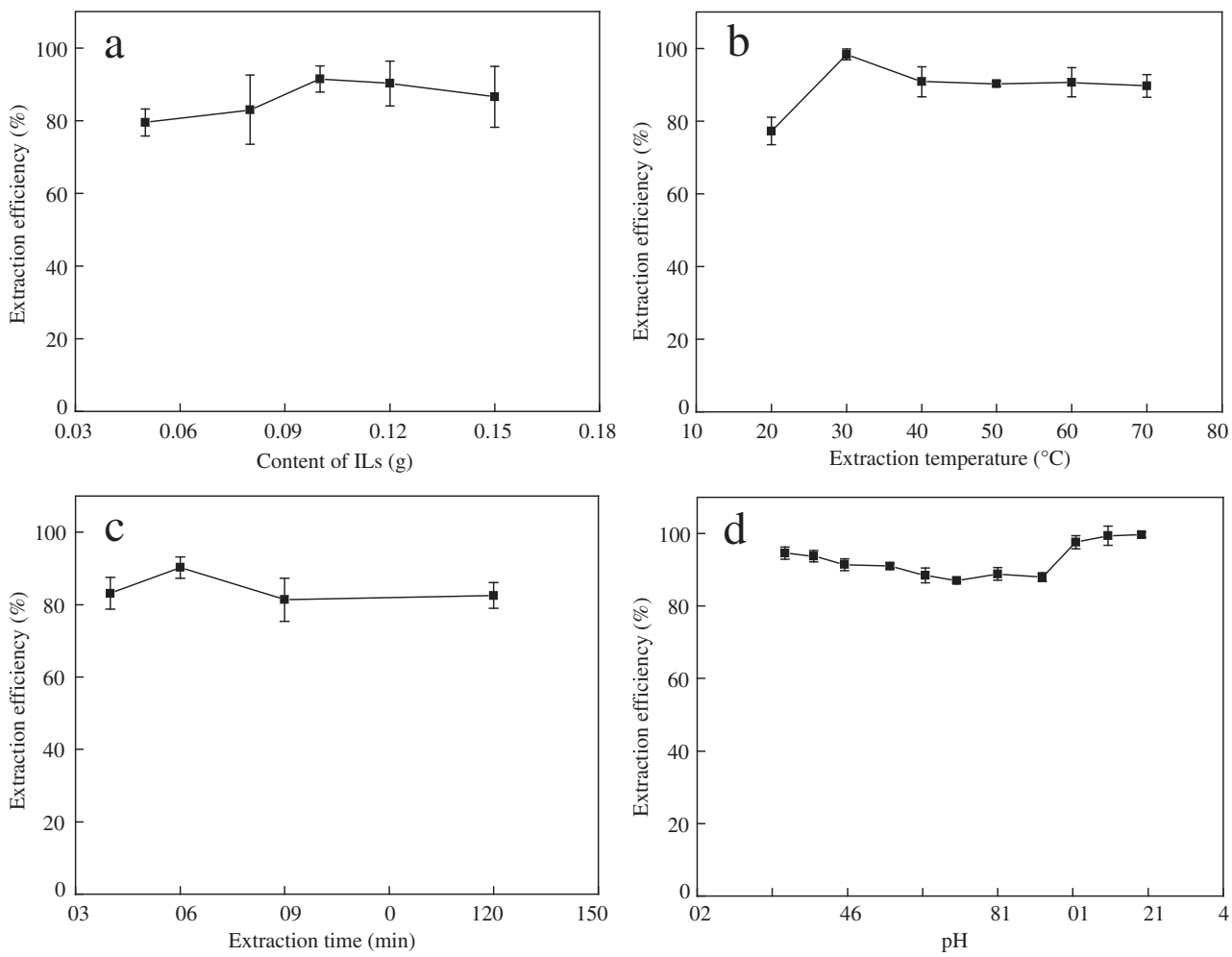

Fig. 3 - Effect of extraction conditions: effects of IL content (a); effect of extraction temperature (b); effect of extraction time (c); effect of $\mathrm{pH}(\mathrm{d})$. 
agents were always used during the extraction procedure to prevent the interference of $\mathrm{Ag}^{+}$(Liu et al., 2009a; Chao et al., 2011; Li et al., 2013). In this study, in order to test the interference of $\mathrm{Ag}^{+}$, dispersions with constant AgNP (0.931 mg/L) and varied $\mathrm{Ag}^{+}(0,0.1,0.2,0.5,1,2,5,10 \mathrm{mg} / \mathrm{L})$ concentrations were mixed, and the extraction was performed at optimized conditions. Results (Fig. 4) indicated that the interference of $\mathrm{Ag}^{+}$without complexing agents could be considered negligible when the concentration of $\mathrm{Ag}^{+}$was lower than $2 \mathrm{mg} / \mathrm{L}$. It could be seen that IL-DLLME showed higher selection for AgNPs than $\mathrm{Ag}^{+}$.

Besides $\mathrm{Ag}^{+}$, other cations commonly found in environmental and biological samples such as $\mathrm{K}^{+}, \mathrm{Na}^{+}, \mathrm{Ca}^{2+}$ and $\mathrm{Mg}^{2+}$ could affect the extraction of AgNPs. Therefore mixtures of AgNPs $(0.46 \mu \mathrm{g} / \mathrm{mL})$ with different concentrations of $\mathrm{KNO}_{3}, \mathrm{NaNO}_{3}$, $\mathrm{Ca}\left(\mathrm{ClO}_{4}\right)_{2}$ and $\mathrm{Mg}\left(\mathrm{ClO}_{4}\right)_{2}$ were extracted and determined under the optimized extraction conditions, respectively. Other relevant ions such as $\mathrm{Mn}^{2+}, \mathrm{Co}^{2+}, \mathrm{Zn}^{2+}, \mathrm{Ni}^{2+}, \mathrm{Cu}^{2+}, \mathrm{Fe}^{2+}$ were also tested for the investigation of environmental samples. As shown in Fig. 5, all these ions had little influence on the extraction efficiency of AgNPs.

\subsection{Analytical performance}

The method performance, such as linearity of calibration curve, reproducibility and detection limit under the optimized conditions, was evaluated. Eleven solutions containing 0, 1.0, 2.0, 5.0, 10, 20, 50, 100, 300, 500 and $1000 \mu \mathrm{g} / \mathrm{L}$ of AgNPs were determined, and the obtained linearity was very satisfactory with correlation coefficients $\left(r^{2}\right)$ of 0.9992 over the entire range of 0-1000 $\mu \mathrm{g} / \mathrm{L}$, with 0.9926 in the range of $0-300 \mu \mathrm{g} / \mathrm{L}$, and 0.9861 in the range of 0-50 $\mu \mathrm{g} / \mathrm{L}$ AgNPs, respectively. The spiked recovery of AgNPs was $84.4 \%$ with a relative standard deviation (RSD) of $3.8 \%(n=6)$ at a spiking level of $5 \mu \mathrm{g} / \mathrm{L}$, and $89.7 \%$ with a RSD of $2.2 \%(n=6)$ at a spiking level of $300 \mu \mathrm{g} / \mathrm{L}$, respectively. The detection limit, defined as 3 times the baseline noise $(\mathrm{S} / \mathrm{N}=3)$, was $0.01 \mu \mathrm{g} / \mathrm{L}$. This detection limit meets the requirement for detection of AgNPs in environmental samples, as the model estimated that the concentration of AgNPs in environmental water samples was about $0.03 \mu \mathrm{g} / \mathrm{L}$ (Mueller and Nowack, 2008).

\subsection{Sample analysis}

To further evaluate the applicability of the developed method, the influent and effluent of a WWTP, river water and lake water samples were analyzed. The $\mathrm{pH}$ values of these water samples were in the range of 6-8, which had little influence on the extraction efficiency as shown in Fig. 3d, so these samples could be used directly after filtration without $\mathrm{pH}$ adjustment. As seen from results shown in Table 1, the total Ag contents in the non-spiked samples were in the range of $0.018-0.05 \mu \mathrm{g} / \mathrm{L}$, while AgNPs were not found, as their concentration was below the limit of quantification. The recoveries at spiked levels of $0.11-4.7 \mu \mathrm{g} / \mathrm{L}$ of AgNPs were in the range of $71.0 \%-$ $90.9 \%$, which was satisfactory considering the low spiking levels.
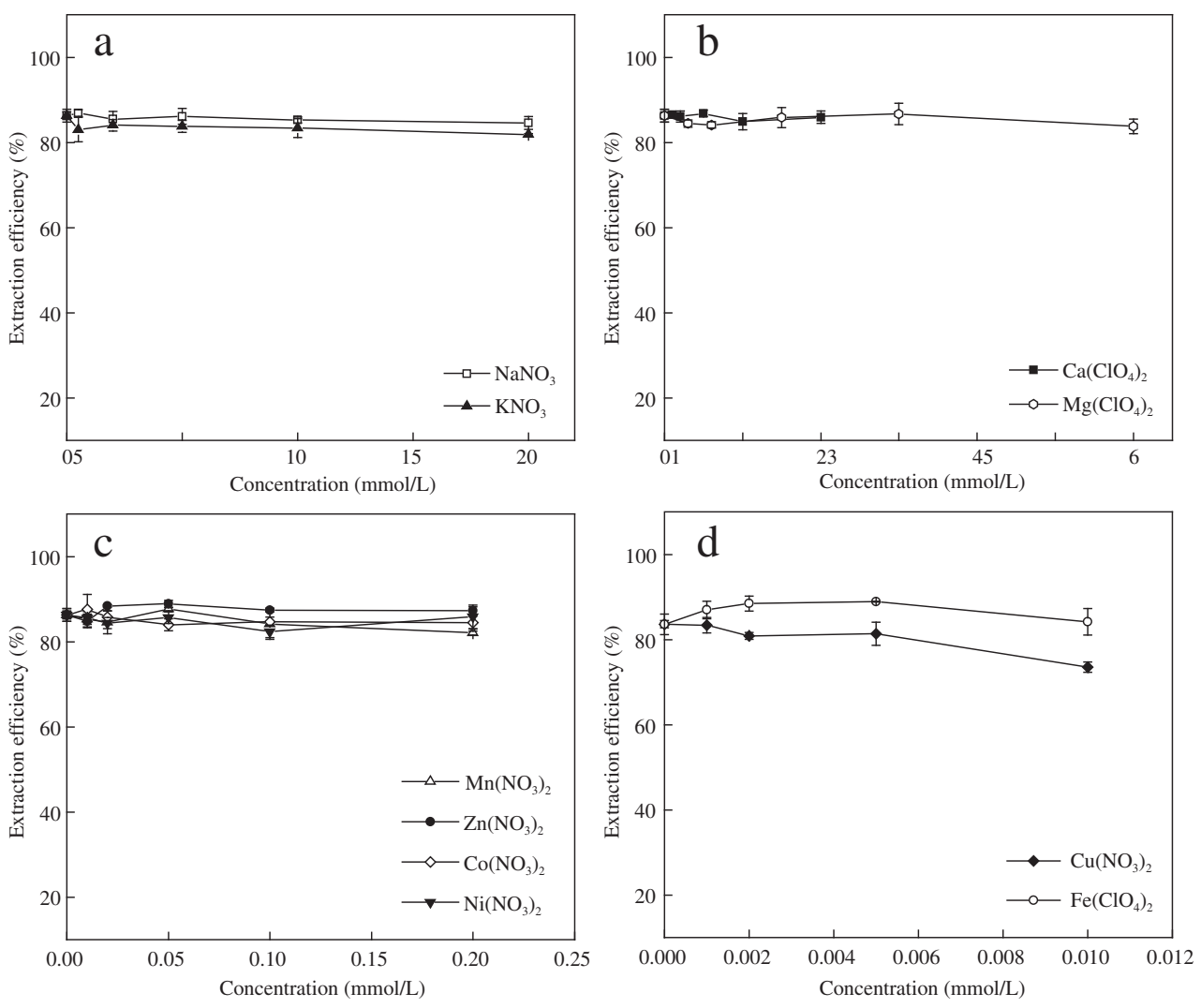

Fig. 5 - Effects of different cations on the extraction efficiency of AgNPs. A $10 \mathrm{~mL}$ mixture of 0.46 mg/L AgNPs with 1\% (W/V) $[\mathrm{OMIM}]\left[\mathrm{PF}_{6}\right]$ was adopted for studying the effect of varied contents of $\mathrm{K}^{+}, \mathrm{Na}^{+}(\mathrm{a}), \mathrm{Ca}^{2+}$ and $\mathrm{Mg}^{2+}(\mathrm{b}), \mathrm{Mn}^{2+}, \mathrm{Co}^{2+}, \mathrm{Zn}^{2+}, \mathrm{Ni}^{2+}(\mathrm{c})$ and $\mathrm{Cu}^{2+}, \mathrm{Fe}^{2+}(\mathrm{d})$. The mixture was incubated at $30^{\circ} \mathrm{C}$ for $30 \mathrm{~min}$. 


\section{Table 1 - Determination of AgNPs in environmental waters.}

\begin{tabular}{|c|c|c|c|c|c|}
\hline Sample & $\mathrm{pH}$ & $\begin{array}{l}\text { Detected total Ag } \\
(\mu g / \mathrm{L})\end{array}$ & $\begin{array}{l}\text { Spiked AgNPs } \\
(\mu \mathrm{g} / \mathrm{L})\end{array}$ & $\begin{array}{l}\text { Detected AgNPs after spiking } \\
(\mu \mathrm{g} / \mathrm{L})\end{array}$ & $\begin{array}{c}\text { Recovery of AgNPs } \\
(\%)\end{array}$ \\
\hline \multirow[t]{2}{*}{ Influents of WWTP } & 7.70 & $0.050 \pm 0.000$ & 0.93 & $0.66 \pm 0.03$ & $71.0 \pm 2.8$ \\
\hline & & & 4.72 & $3.99 \pm 0.05$ & $84.5 \pm 1.1$ \\
\hline \multirow[t]{2}{*}{ Effluents of WWTP } & 7.67 & $0.026 \pm 0.001$ & 0.93 & $0.70 \pm 0.05$ & $75.3 \pm 4.9$ \\
\hline & & & 4.72 & $4.15 \pm 0.18$ & $87.9 \pm 3.8$ \\
\hline \multirow[t]{3}{*}{ Jingmi River } & 7.95 & $0.031 \pm 0.005$ & 0.11 & $0.08 \pm 0.001$ & $72.7 \pm 1.3$ \\
\hline & & & 0.53 & $0.46 \pm 0.002$ & $86.8 \pm 0.3$ \\
\hline & & & 0.96 & $0.78 \pm 0.005$ & $81.3 \pm 0.5$ \\
\hline \multirow[t]{3}{*}{ Yongding River } & 8.05 & $0.033 \pm 0.005$ & 0.11 & $0.10 \pm 0.005$ & $90.9 \pm 5.1$ \\
\hline & & & 0.53 & $0.47 \pm 0.004$ & $88.7 \pm 0.7$ \\
\hline & & & 0.96 & $0.72 \pm 0.01$ & $75.0 \pm 1.4$ \\
\hline Summer Palace Fuhai & 8.05 & $0.019 \pm 0.001$ & 0.89 & $0.74 \pm 0.01$ & $83.1 \pm 1.2$ \\
\hline Olympic Green River & 8.12 & $0.018 \pm 0.001$ & 0.89 & $0.73 \pm 0.03$ & $82.0 \pm 2.9$ \\
\hline
\end{tabular}

WWTP: wastewater treatment plant. Data are presented as Mean $\pm \mathrm{SD}, n=3$.

\section{Conclusions}

For the first time, an IL-based dispersive liquid-liquid microextraction method (IL-DLLME) was developed for the selective extraction of AgNPs in water samples. This method provided extraction efficiencies up to $90 \%$, enrichment factor of over 90 , and detection limit of $0.01 \mu \mathrm{g} / \mathrm{L}$ by coupling with ICP-MS detection. The UV-Vis and TEM detection demonstrated that this extraction procedure preserved the sizes and shapes of AgNPs. The method satisfied the requirement for 'real' water samples, and results showed that common coexisting ions such as $\mathrm{K}^{+}$, $\mathrm{Na}^{+}, \mathrm{Ca}^{2+}$ and $\mathrm{Mg}^{2+}$ and other environmentally relevant ions such as $\mathrm{Cu}^{2+}, \mathrm{Fe}^{2+}, \mathrm{Mn}^{2+}, \mathrm{Co}^{2+}, \mathrm{Zn}^{2+}$ and $\mathrm{Ni}^{2+}$ had very limited influence on the extraction efficiency, which meant that IL-DLLME provided a novel approach for tracing AgNPs in environmental waters. This proposed method is easy to conduct, sensitive and low cost, and has considerable potential in studying the behavior and fate of AgNPs in the environment.

\section{Acknowledgments}

This work was supported by the National Natural Science Foundation of China (No. 21207124), Research Project of Beijing Municipal Education Commission (No. KM201110005009) and the Special Fund for Quality Inspection Administration Public Welfare Scientific Research Funding (No. 2012104001).

\section{R E F E R E N C E S}

Anthemidis, A.N., Ioannou, K.G., 2012. Sequential injection ionic liquid dispersive liquid-liquid microextraction for thallium preconcentration and determination with flame atomic absorption spectrometry. Anal. Bioanal. Chem. 404 (3), 685-691.

Ashkenani, H., Taher, M.A., 2012. Use of ionic liquid in simultaneous microextraction procedure for determination of gold and silver by ETAAS. Microchem. J. 103, 185-190.

Badawy, A.M.E., Silva, R.G., Morris, B., Scheckel, K.G., Suidan, M.T., Tolaymat, T.M., 2011. Surface charge-dependent toxicity of silver nanoparticles. Environ. Sci. Technol. 45 (1), 283-287.

Bednar, A.J., Poda, A.R., Mitrano, D.M., Kennedy, A.J., Gray, E.P., Ranville, J.F., et al., 2013. Comparison of on-line detectors for field flow fractionation analysis of nanomaterials. Talanta 104, 140-148.

Benn, T.M., Westerhoff, P., 2008. Nanoparticle silver released into water from commercially available sock fabrics. Environ. Sci. Technol. 42 (11), 4133-4139.

Blaser, S.A., Scheringer, M., MacLeod, M., Hungerbühler, K., 2008. Estimation of cumulative aquatic exposure and risk due to silver: contribution of nano-functionalized plastics and textiles. Sci. Total Environ. 390 (2-3), 396-409.

Burkowska-But, A., Sionkowski, G., Walczak, M., 2014. Influence of stabilizers on the antimicrobial properties of silver nanoparticles introduced into natural water. J. Environ. Sci. 26 (3), 542-549.

Carlson, C., Hussain, S.M., Schrand, A.M., Braydich-Stolle, L.K., Hess, K.L., Jones, R.L., et al., 2008. Unique cellular interaction of silver nanoparticles: size-dependent generation of reactive oxygen species. J. Phys. Chem. B 112 (43), 13608-13619.

Chao, J.B., Liu, J.F., Yu, S.J., Feng, Y.D., Tan, Z.Q., Liu, R., et al., 2011. Speciation analysis of silver nanoparticles and silver ions in antibacterial products and environmental waters via cloud point extraction-based separation. Anal. Chem. 83 (17), 6875-6882.

Chen, S., Zhong, Y.S., Cheng, S.Y., Qian, T., Sun, H., 2011. Development of an ionic liquid-based dispersive liquid-liquid micro-extraction method for the determination of phthalate esters in water samples. J. Sep. Sci. 34 (13), 1503-1507.

Elle, R.E., Gaillet, S., Vidé, J., Romain, C., Lauret, C., Rugani, N., et al., 2013. Dietary exposure to silver nanoparticles in Sprague-Dawley rats: effects on oxidative stress and inflammation. Food Chem. Toxicol. 60, 297-301.

Emam, H.E., Manian, A.P., Široká, B., Duelli, H., Redl, B., Pipal, A., et al., 2013. Treatments to impart antimicrobial activity to clothing and household cellulosic-textilese - why "Nano"-silver? J. Clean. Prod. 39, 17-23.

Farré, M., Sanchís, J., Barceló, D., 2011. Analysis and assessment of the occurrence, the fate and the behavior of nanomaterials in the environment. Trends Anal. Chem. 30 (3), 517-527.

Han, D., Row, K.H., 2010. Recent applications of ionic liquids in separation technology. Molecules 15 (4), 2405-2426.

Huang, H.L., Wang, H.P., Wei, G.T., Sun, I.W., Huang, J.F., Yang, Y.W., 2006. Extraction of nanosize copper pollutants with an ionic liquid. Environ. Sci. Technol. 40 (15), 4761-4764.

Huang, H.L., Wang, H.P., Eyring, E.M., Chang, J.E., 2009. Recovery of nanosize zinc from phosphor wastes with an ionic liquid. Environ. Chem. 6 (3), 268-272.

Jiang, X.Y., Zhang, H., Chen, X.Q., 2011. Determination of phenolic compounds in water samples by HPLC following ionic liquid dispersive liquid-liquid microextraction and cold-induce $d$ aggregation. Microchim. Acta 175 (3-4), 341-346. 
Khan, S., Mukherjee, A., Chandrasekaran, N., 2011. Silver nanoparticles tolerant bacteria from sewage environment. J. Environ. Sci. 23 (2), 346-352.

Lee, C.Y., Huang, C.H., Wei, G.T., 2010. Behaviors of ionic liquids in the phase transfer of aqueous metal nanoparticles. Colloids Surf. A Physicochem. Eng. Asp. 367 (1-3), 24-30.

Li, L.X.Y., Leopold, K., Schuster, M., 2012. Effective and selective extraction of noble metal nanoparticles from environmental water through a noncovalent reversible reaction on an ionic exchange resin. Chem. Commun. 48 (73), 9165-9167.

Li, L.X.Y., Hartmann, G., Döblinger, M., Schuster, M., 2013. Quantification of nanoscale silver particles removal and release from municipal wastewater treatment plants in Germany. Environ. Sci. Technol. 47 (13), 7317-7323.

Liu, J.F., Jönsson, J.Å., Jiang, G.B., 2005. Application of ionic liquids in analytical chemistry. Trends Anal. Chem. 24 (1), 20-27.

Liu, J.F., Chao, J.B., Liu, R., Tan, Z.Q., Yin, Y.G., Wu, Y., et al., 2009a. Cloud point extraction as an advantageous preconcentration approach for analysis of trace silver nanoparticles in environmental waters. Anal. Chem. 81 (15), 6496-6502.

Liu, R., Liu, J.F., Yin, Y.G., Hu, X.L., Jiang, G.B., 2009b. Ionic liquids in sample preparation. Anal. Bioanal. Chem. 393 (3), 871-883.

Liu, J.F., Yu, S.J., Yin, Y.G., Chao, J.B., 2012. Methods for separation, identification, characterization and quantification of silver nanoparticles. Trends Anal. Chem. 33, 95-106.

López-García, I., Vicente-Martínez, Y., Hernández-Cordoba, M., 2012. Determination of very low amounts of chromium(III) and (VI) using dispersive liquid-liquid microextraction by in situ formation of an ionic liquid followed by electrothermal atomic absorption spectrometry. J. Anal. At. Spectrom. 27 (5), 874-880.

López-García, I., Vicente-Martínez, Y., Hernández-Córdoba, M., 2014. Speciation of silver nanoparticles and Ag(I) species using cloud point extraction followed by electrothermal atomic absorption spectrometry. Spectrochim. Acta B At. Spectrosc. 101, 93-97.

López-Lorente, A.I., Simonet, B.M., Valcárcel, M., 2012. Rapid analysis of gold nanoparticles in liver and river water samples. Analyst 137 (15), 3528-3534.

Losert, S., von Goetz, N., Bekker, C., Fransman, W., Wijnhoven, S.W.P., Delmaar, C., et al., 2014. Human exposure to conventional and nanoparticle-containing sprays: a critical review. Environ. Sci. Technol. 48 (10), 5366-5378.

Meyer, D.E., Curran, M.A., Gonzalez, M.A., 2011. An examination of silver nanoparticles in socks using screening-level life cycle assessment. J. Nanoparticle Res. 13 (1), 147-156.

Mueller, N.C., Nowack, B., 2008. Exposure modeling of engineered nanoparticles in the environment. Environ. Sci. Technol. 42 (12), 4447-4453.

Ojeda, C.B., Rojas, F.S., 2011. Separation and preconcentration by dispersive liquid-liquid microextraction procedure: recent applications. Chromatographia 74 (9-10), 651-679.

Pal, S., Tak, Y.K., Song, J.M., 2007. Does the antibacterial activity of silver nanoparticles depend on the shape of the nanoparticle? A study of the Gram-negative bacterium Escherichia coli. Appl. Environ. Microbiol. 73 (6), 1712-1720.

Quadros, M.E., Marr, L.C., 2011. Silver nanoparticles and total aerosols emitted by nanotechnology-related consumer spray products. Environ. Sci. Technol. 45 (24), 10713-10719.

Rezaee, M., Assadi, Y., Hosseini, M.M., Aghaee, E., Ahmadi, F., Berijani, S., 2006. Determination of organic compounds in water using dispersive liquid-liquid microextraction. J. Chromatogr. A 1116 (1-2), 1-9.
Sallum, L.F., Soares, F.L.F., Ardila, J.A., Carneiro, R.L., 2014. Optimization of SERS scattering by Ag-NPs-coated filter paper for quantification of nicotinamide in a cosmetic formulation. Talanta 118, 353-358.

Shahverdi, A.R., Fakhimi, A., Shahverdi, H.R., Minaian, S., 2007. Synthesis and effect of silver nanoparticles on the antibacterial activity of different antibiotics against Staphylococcus aureus and Escherichia coli. Nanomed.: Nanotechnol., Biol. Med. 3 (2), 168-171.

Sharma, V.K., Siskova, K.M., Zboril, R., Gardea-Torresdey, J.L., 2014. Organic-coated silver nanoparticles in biological and environmental conditions: fate, stability and toxicity. Adv. Colloid Interf. Sci. 204, 15-34.

Sondi, I., Salopek-Sondi, B., 2004. Silver nanoparticles as antimicrobial agent: a case study on E. coli as a model for Gram-negative bacteria. J. Colloid Interface Sci. 275 (1), 177-182.

Stuart, E.J.E., Zhou, Y.G., Rees, N.V., Compton, R.G., 2012. Determining unknown concentrations of nanoparticles: the particle-impact electrochemistry of nickel and silver. RSC Adv. 2 (17), 6879-6884.

Tan, Z.Q., Liu, J.F., Pang, L., 2012. Advances in analytical chemistry using the unique properties of ionic liquids. Trends Anal. Chem. 39, 218-227.

Tian, H., Eom, H.J., Moon, S., Lee, J., Choi, J., Chung, Y.D., 2013. Development of biomarker for detecting silver nanoparticles exposure using a GAL4 enhancer trap screening in Drosophila. Environ. Toxicol. Pharmacol. 36 (2), 548-556.

Tiede, K., Boxall, A.B.A., Tiede, D., Tear, S.P., David, H., Lewis, J., 2009. A robust size-characterisation methodology for studying nanoparticle behaviour in 'real' environmental samples, using hydrodynamic chromatography coupled to ICP-MS. J. Anal. At. Spectrom. 24 (7), 964-972.

Tolaymat, T.M., El Badawy, A.M., Genaidy, A., Scheckel, K.G., Luxton, T.P., Suidan, M., 2010. An evidence-based environmental perspective of manufactured silver nanoparticle in syntheses and applications: a systematic review and critical appraisal of peer-reviewed scientific papers. Sci. Total Environ. 408 (5), 999-1006.

Vázquez, M.M.P., Vázquez, P.P., Galera, M.M., García, M.D.G., 2012. Determination of eight fluoroquinolones in groundwater samples with ultrasound-assisted ionic liquid dispersive liquid-liquid microextraction prior to high-performance liquid chromatography and fluorescence detection. Anal. Chim. Acta 748, 20-27.

Yu, S.J., Yin, Y.G., Liu, J.F., 2012. Silver nanoparticles in the environment. Environ. Sci.: Processes Impacts 15 (1), 78-92.

Zhang, J.H., Li, M., Yang, M.Y., Peng, B., Li, Y.B., Zhou, W.F., et al., 2012. Magnetic retrieval of ionic liquids: fast dispersive liquid-liquid microextraction for the determination of benzoylurea insecticides in environmental water samples. J. Chromatogr. A 1254, 23-29.

Zhang, P.J., Hu, L., Lu, R.H., Zhou, W.F., Gao, H.X., 2013. Application of ionic liquids for liquid-liquid microextraction. Anal. Methods 5 (20), 5376-5385.

Zhao, C.M., Wang, W.X., 2010. Biokinetic uptake and efflux of silver nanoparticles in daphnia magna. Environ. Sci. Technol. 44 (19), 7699-7704.

Zhao, D.B., Fei, Z.F., Ang, W.H., Dyson, P.J., 2006. A strategy for the synthesis of transition-metal nanoparticles and their transfer between liquid phases. Small 2 (7), 879-883. 